\title{
An Accidental Death of Pregnant Gilt
}

\author{
Sarojini Mahanta Tamuli ${ }^{1}$, Kongkon Jyoti Dutta ${ }^{1}$, Amrit Gogoi ${ }^{1}$, \\ Kabita Sarma $^{2}$, Binita Barua ${ }^{1}$ and Tirtha Nath Upadhyaya ${ }^{1}$ \\ ${ }^{1}$ Department of Pathology, ${ }^{2}$ Department of Anatomy and Histology, CVSc, \\ AAU, Khanapara, Guwahati-22, India \\ *Corresponding author
}

\section{A B S T R A C T}

\section{Keywords \\ Asphyxia, \\ Farrowing crate, \\ Gilt, Guard pipe \\ Article Info \\ Accepted: \\ 10 May 2019 \\ Available Online: \\ 10 June 2019}

A carcass of a pregnant gilt of one year old was subjected for post mortem examination and was due for farrowing after 16 days. The day before death, the gilt introduced her head into the farrowing crate through the lower most guard pipe. After about 1/1/2 hrs of struggle she was released forcefully by the attendants. The gilt died after 2 hours. Based on history, circumstantial evidences and gross lesions the cause of death was ascertained as asphyxia and shock. This investigation detected that the gap of the lower guard pipe was not perfect for which the gilt could enter her head but unable to released her head. Therefore, pig farmers should take appropriate precaution to avoid such type of incidences in the farm.

\section{Introduction}

Accidental death of animal can be encountered due to various reasons, such as hanging, strangulation, drowning, eletrocution, lightning, burning, automobile accidents ${ }^{1,2}$. The pathology of death in such cases was reported as asphyxia ${ }^{3,4}$. But an unusual death of pregnant gilt in the farrowing crate was not recorded yet. Hence, this case report has been considered as valuable information for the farmers as well as for the veterinary practitioners. A gilt of one year of age was brought to the department of pathology, College of Veterinary Science,
AAU, Khanapara-22 for postmortem examination. The history of death of one year old gilt was reported as due to an accident. The gilt was in late pregnancy and farrowing was due after 16 days. The day before death, the gilt inserted her head into the farrowing crate through the lower most guard pipe (Fig. 1). Based on history, she turned over her head, pushed forward and then got locked.

The body size and weight were optimum as the animal was in last fortnight of pregnancy. After 1 to 1 and 1/2 hrs of struggle, she could be released forcefully by the attendants. The animal was over exhausted and fatigue. There 
were remarkable gross changes in the carcass. The tissues for microscopic changes could not be collected as the carcass was moderately autolysed.

At necropsy, the inner thigh region of the right hind limb was markedly swollen and cyanotic in appearance (Fig. 2). On incision, severe haemorrhage and mass of clotted blood were revealed (Fig. 3). The brachiocephalicus muscle was found to be ruptured ${ }^{5}$. The noticeable lesion observed was the complete fracture of right femur just below the hip joint. Some of the workers opined that the mechanical forces cause fracture of the bone in response to stress ${ }^{6}$. This remarkable fracture of bone and muscle rupture was the result of forceful pulling of leg by the attendants to release her head from the lower most guard pipe.

Fig.1,2\&3 Photograph of the farrowing. Crate in which the gilt entered her head through the lower most guard, markedly swollen and cyanotic inner thigh of right hind limb \& dead fetuses in the mother's womb

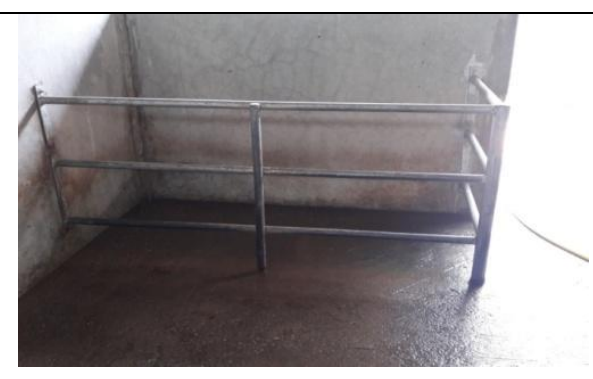

Fig.1 Photograph of the farrowing. Crate in which the gilt entered her head through the lower most guard

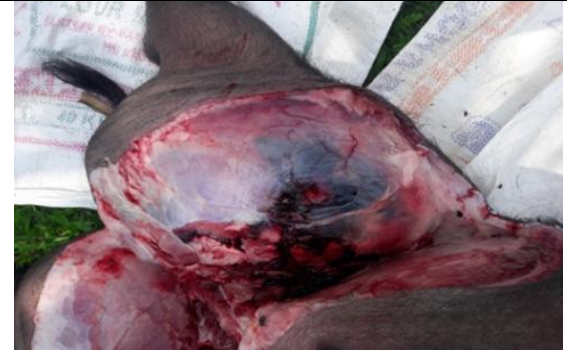

Fig.2 Markedly swollen and cyanotic inner thigh of right hind limb

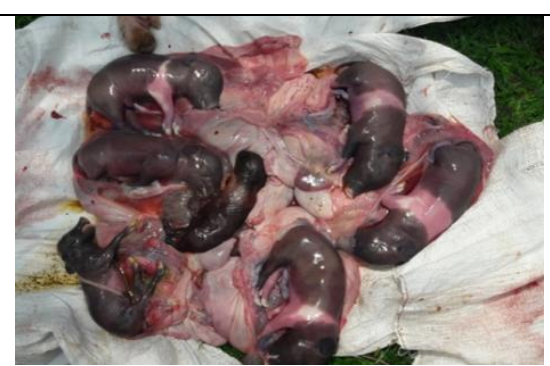

Fig.3 Dead fetuses in the mother's womb
The neck region was found highly swollen. There was petechial hemorrhage in the subcutaneous tissue and neck muscle. The tracheal mucosa showed congestion and petechial harmorrhages due to compression, venous obstruction and anoxia. The epicardium and the lungs revealed petechiae as a result of hypercapnea causing capillaries to dilate and leak blood ${ }^{7}$. Both the lungs were enlarged, pale and severely emphysematous. This type of emphysema is common in violent struggle at the time of death ${ }^{8}$. The lesions of the heart revealed severe petechiae to ecchymotic haemorrhages in the left ventricular endocardium. The right ventricle was markedly dilated and contained current jelly clot, indicating sudden death ${ }^{9}$. The carotid arteries might have compressed by the guard pipe of farrowing crate that led to anoxia. It was ascertained that the gilt died of shock and asphyxia. The gravid uterus had eight dead fetuses (Fig. 3). This report has suggested that the pig farmers should always take appropriate measure to avoid such unwanted incidences. Such type of incidence can be avoided with a little effort by sectioning the iron guard pipe with the help of electrical welding machine or saw. Moreover, at the time of building of infrastructure a little attention has to be given for making the suitable gap of guard pipes within $12 \mathrm{~cm}$ to $15 \mathrm{~cm}$. The case has been reported from the 
pathological point of view for alerting the veterinarian for future precaution.

\section{References}

1. Gresham GA, 1975. Asphyxia and poisoning. In a colour Atlas of Forensic Pathology. pp. 235-273. Walf Medical Books. 10 Earlham Street. London. WC2.

2. Tamuli S.M. 2007. A Case report on accidental hanging of a heifer. Intaspolyvet, 8(I): 38 .

3. Sharma SN; Galhot AK and Tanwar RK. 2003. Asphyxia. Veterinary jurisprudence. NBS Publishers and distributors, Bikaner- 334001 India. 5th ed. Pp 73-79.

4. Biswas G, 2015. Asphyxia. Review of forensic medicine \& toxicology. 3rd ed. Jaypee Brothers Medical
Publishers.Pp161-164

5. Getty R. 1975. Osteology and Myology of porcine. Sisson and Grossman's Anatomy of the Domestic Animals. W.B. Saunders Co. Philadelphia. 5th ed. 2: 1216-1267.

6. Zachary JF and Mc Gavin M Donald. 2012. Pathologic Basis of Veterinary Diseases. Elsevier. China. $5^{\text {th }}$ edn, Pp. 931.

7. Jones TC and Hunt RD. 1983 Disturbances of circulation. Veterinary Pathology. 5th ed. Lea and Febiger, Verghese. Pp 141174.

8. Strawbridge HTG. 1960. Chronic pulmonary emphysema. Histological review. Am. J. Pathol. 37: 161- 174.

9. Sastry GA and Rao, 2005. Cardiovascular system. 7th ed. CBS Publishers and Distributors. DaryaGanj. New Delhi.

\section{How to cite this article:}

Sarojini Mahanta Tamuli, Kongkon Jyoti Dutta, Amrit Gogoi, Kabita Sarma, Binita Barua and Tirtha Nath Upadhyaya. 2019. An Accidental Death of Pregnant Gilt. Int.J.Curr.Microbiol.App.Sci. 8(06): 831-833. doi: https://doi.org/10.20546/ijcmas.2019.806.100 